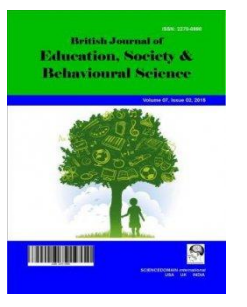

\author{
British Journal of Education, Society \& \\ Behavioural Science \\ 9(3): 161-175, 2015, Article no.BJESBS.2015.136 \\ ISSN: 2278-0998 \\ SCIENCEDOMAIN international \\ www.sciencedomain.org
}

\title{
Stress in U.K. Mental Health Training: A Multi-dimensional Comparison Study
}

\author{
John Galvin ${ }^{1 *}$ and Andrew P. Smith ${ }^{1}$ \\ ${ }^{1}$ Centre for Occupational and Health Psychology, School of Psychology, Cardiff University, UK.
}

Authors' contributions

This work was carried out in collaboration between both authors. Author JG was involved in the conception and design of the study, carried out the statistical analyses and interpreted the data.

Author JG drafted and revised the article. Author APS supervised the project and contributed knowledge and experience to the conception, design and analysis stages of the research. Author APS also revised the article for important intellectual content. Both authors read and approved the final manuscript to be published.

\section{Article Information}

DOI: 10.9734/BJESBS/2015/18519 Editor(s):

(1) Chan Shen, Department of Biostatistics, University of Texas, USA.

Reviewers:

(1) Michelle Beckford, Saint Peter's University, USA.

(2) Maciej Płaszewski, University of Physical Education, Warsaw, Poland. Complete Peer review History: http://www.sciencedomain.org/review-history.php?iid=1174\&id=21\&aid=9470

Original Research Article

Received $26^{\text {th }}$ April 2015

Accepted $16^{\text {th }}$ May 2015

Published $28^{\text {th }}$ May 2015

\section{ABSTRACT}

Aims: This paper describes a comparison study of trainee clinical psychologists, psychiatric nursing students and $\mathrm{PhD}$ students using a multi-dimensional model of stress.

Methodology: A total of 168 trainee clinical psychologists, 94 psychiatric nursing students and 253 $\mathrm{PhD}$ students completed an online questionnaire. Multiple risk factors were measured, including work characteristics, appraisals, coping, health behaviours, childhood experiences and mental health outcomes.

Results: Trainee clinical psychologists reported the highest levels of demands, perceived stress and psychological ill health. Psychiatric nursing students reported the highest levels of emotionbased coping, which needs to be addressed. Alcohol consumption appears to be an important coping strategy employed by psychiatric nursing students. Negative childhood experiences were significantly higher for mental health training groups than $\mathrm{PhD}$ students.

Conclusion: Where other research focusing on stress at work or in training environments tends to consider only a small number of factors in isolation, this study considers multiple factors on 
outcomes. This approach is more likely to be representative of real-life situations, in which students are exposed to multiple hazards.

Keywords: Mental health training; trainee clinical psychologists; psychiatric nursing students; mental health nursing; stress; health; wellbeing.

\section{INTRODUCTION}

\subsection{Training in the Mental Health Professions}

Research focusing on mental health professionals has commonly found that this population report high levels of stress [1-3]. For this reason, research attention has not only been focused on their work environment, but also their training period [4-6]. The training period is an important time, during which the student acquires the skills and experiences required for the profession. Additionally, training provides a unique opportunity to develop the capabilities of the individual in terms of their own personal resources and coping strategies. The present study focuses on two types of mental health professionals in training: Trainee clinical psychologists and psychiatric nursing students. Data were also collected from a sample of $\mathrm{PhD}$ students who acted as a comparison group.

There are important similarities and differences between the selected groups. Clinical psychologists and psychiatric nurses in the UK offer very similar services but at the same time maintain their own distinctive roles. Both groups work towards the common goal of understanding the mental health needs of their patients with the intention to change undesirable thoughts, emotions and behaviours, with the main objective being to enhance the wellbeing of patients and allow them to live more independently. Indeed, both groups will commonly work together in multi-disciplinary teams and previous research has investigated ways in which they can work together more effectively [7].

Trainee clinical psychologists are engaged in a Doctorate in Clinical Psychology course and psychiatric nursing students are engaged in a Bachelor of Nursing degree. During their training, both groups will be exposed to academic and clinical demands, with $50 \%$ of the course involving academic work and the other $50 \%$ involving clinical practice. Most PhD students however, the comparison group in this study, are solely academic and do not engage in the treatment and management of patients. Nonetheless, in a similar way to trainee clinical psychologists and psychiatric nursing students, they are required to meet academic deadlines and therefore report the common stressors related to being a student [8]. Including PhD students in this comparison study is helpful, as we hope to tease out the additional strains of the clinical aspect of the mental health groups.

The clinical component of the mental health courses involves the students undergoing placements in the NHS, an environment renowned for being stressful. Indeed, during times of austerity and increasing pressure on NHS services, NHS workers are reporting higher levels of stress than ever before. For example, the 2013 NHS staff survey [9] revealed $39 \%$ of the staff reported work-related stress, the highest levels reported since the surveys inception in 2003. Additionally, only $44 \%$ of staff surveyed said they believe the organisation takes positive action on health and wellbeing. The data on psychiatric nurses revealed $46 \%$ reported workrelated stress, compared to $40 \%$ of learning disabilities nurses, $39 \%$ child nurses and $39 \%$ adult nurses. Thirty-seven percent of clinical psychologists reported work-related stress which was higher than many other professions, including the $33 \%$ of medical and dental staff who reported work-related stress. Therefore, it is important to investigate stress in students who undertake clinical placements in such high stress work environments.

\subsection{Stress in Trainee Clinical Psychologists}

There is a dearth of published literature focusing on stress in trainee clinical psychologists in both the U.K. and internationally. In a recent review of the area, Pakenham and Stafford-Brown [5] found only one published quantitative study that examined the sources and levels of stress in trainee clinical psychologists. For this reason, their review mainly focused on findings from other mental health practitioners in an attempt to generalise these findings. The one study that did report sources and levels of stress in this group was by Cushway [10], who found that $59 \%$ of her 
sample scored above the clinical cut-off for distress on the General Health Questionnaire [11], which was considerably higher than other groups. Six underlying factors were reported; workload, lack of social support, client difficulties and distress, self-doubt, course structure and poor supervision. These findings reflect the insecurities and worries that are commonly found among individuals in other mental health occupations, such as those found in studies focusing on psychiatric nursing students $[4,6]$.

\subsection{Stress in Nursing Students}

A great deal of research has been conducted looking at stress in nursing students [12-14]. Indeed this is necessary, particularly within the U.K., where stress has been linked to attrition among nursing students and the NHS has experienced problems with recruitment $[15,16]$. Research has often pointed towards the clinical component of nursing education as being the most stressful [17]. Jones and Johnston [18] investigated stress in nursing students and, in particular, found significant levels of distress around the time of clinical placements. High levels of stress have been shown to lead to higher levels of psychological ill health [19] and lower job satisfaction [20], with negative consequences for the effective functioning of the organisation [21].

However, a limitation of much of the available research focusing on stress in nursing students is that researchers often fail to consider the different specialties of nursing when collecting their data. That is, many studies conducted in the U.K. focus broadly on 'nursing students' rather than considering psychiatric nursing students as a population in their own right. However, this can cause many problems when using such data to inform stress interventions and nursing education policy. Psychiatric nursing students will have their own unique stressors specific to their field, as will students in other areas such as adult, child and learning disabilities settings. A more comprehensive account of the stress process in U.K. psychiatric nursing students is therefore needed and this study adds to this gap in the literature.

One of the most impressive studies focusing specifically on psychiatric nursing students is a qualitative study by Kipping [22], who asked participants $(n=447)$ the open-ended question "looking back over your psychiatric nursing experience, what, if anything, have you found stressful?" Participants reported stressors such as feeling unable to make a difference, the physical environment, problems with their clinical placement, exams/assessments/written work and personal issues outside of the course.

\subsection{Mental Health Professionals Personal Experiences}

Since its introduction by Jung [23], the 'wounded healer' has become a well-established phenomenon in the academic literature and popular culture and suggests that mental health professionals are often compelled to treat clients due to their own personal experiences. Indeed, it has been suggested that mental health professionals are likely to be more susceptible to mental health problems due to a higher prevalence of problems in their personal and home lives. For example, in a large American investigation by Elliott and Guy [24], it was found that qualified female clinical psychologists reported higher levels of physical and sexual abuse, psychiatric history, parental alcoholism and greater dysfunction in their families than other professionals. Similar findings have been found in studies focusing on psychiatrists [25,26] and other groups of psychologists [27].

\subsection{Alcohol and Health Behaviours}

Research has demonstrated that alcohol consumption is not directly related to selfperceived psychological ill health in university students (see Wicki, Kuntsche and Gmel [28] for a review). Pickard et al. [29] interpreted this as an indicator that alcohol is not used to relieve stress. Other researchers [30] have also considered the possibility that alcohol consumption is instead an effective but maladaptive coping strategy.

Other health behaviours, such as diet and exercise have been found to be related to stress in students. For example, Oliver and Wardle [31] found the majority of students in their study $(73 \%)$ reported snacking behaviour when stressed. The explanation given by the authors was that students who are under stress are more likely to choose energy-dense foods rather than non-energy dense foods. Additionally, Lee and Loke [32] found that relatively few university students had a sense of "health responsibility" with only $14 \%$ reporting exercise on a regular basis and less than half ate fruits $(35 \%)$ or vegetables $(48 \%)$ every day. 


\subsection{A Multi-dimensional Approach to Stress}

Very little research focusing on stress considers the effects of multiple factors on outcomes. It is more common for stress researchers to focus their efforts on the nature and effects of a small number of stressors in isolation [33]. However, this approach is unlikely to be representative of real-life situations, in which individuals are exposed to multiple hazards at work. Furthermore, stressors outside of work and individual difference variables will also have an influence on outcomes. The present study adopts a more holistic approach to stress measurement, with group comparisons and a multi-dimensional approach being preferred.

The Demands, Resources and Individual Effects model (DRIVE model) suggested by Mark and Smith [34] is applied to the framework of this study. The original DRIVE model includes factors such as demands, resources, individual differences and outcomes. However, this model was designed to be a flexible framework that allows other relevant variables to be applied [34]. An enhanced DRIVE model was also developed by the authors, which considered a subjective element and includes perceived stress as having an interactive effect. Specifically, the model proposes direct effects on outcomes by each of the other variable groups, as well as an interaction effect of perceived stress on demands and resources. In the present paper, this multidimensional approach to work stress is employed, with work characteristics, coping, appraisals, personality, health behaviours, childhood experiences and outcomes being measured. The effects of multiple factors are explored on three outcomes; perceived stress, job satisfaction and psychological ill health. Additionally, an interactive effect of perceived stress on demands and resources is considered.

\section{METHODS}

\subsection{Participants}

A total of 515 participants completed an online questionnaire. The questionnaire was crosssectional in nature and participant recruitment involved convenience sampling whereby an email advertisement was forwarded to potential participants. Respondents included 168 trainee clinical psychologists recruited from five U.K. clinical psychology courses, 94 psychiatric nursing students from three U.K. nursing courses and $253 \mathrm{PhD}$ students from three institutions. The PhD students were from a wide range of disciplines and some worked across disciplines. They were asked to confirm that their work does not involve patient contact or other substantial clinical work before taking part in the study. All participants were enrolled as full-time students.

The majority of the trainee clinical psychologists were female $(152,90.5 \%)$ with a mean age of 29.41 years $(S D=3.973$, minimum 22 years, maximum 45 years). Most were married or in a relationship $(135,80.8 \%)$ and of White ethnicity $(156,93.4 \%)$. In terms of year of training, there were 51 participants in year one $(30.5 \%), 52$ in year two (31.1\%) and 64 in the final year $(38.3 \%)$ of their training programme. In the psychiatric nursing students group, most were female (81, $86.2 \%$ ) with a mean age of $25.83(\mathrm{SD}=7.567$, minimum 18, maximum 59), were married or in a relationship $(61,64.9 \%)$ and of White ethnicity $(89,94.7 \%)$. Across the years, there were 38 first year $(40.4 \%), 24$ second year $(25.5 \%)$ and 32 final year $(34 \%)$ students. Most PhD respondents were female $(194,76.7 \%)$, mean age of 28.02 years $(S D=6.673$, minimum 21 , maximum 63 ), married or in a relationship $(192,75.9 \%)$ and White ethnicity $(224,88.5 \%)$. There were 64 in year one $(25.3 \%), 71$ in year two $(28.1 \%)$ and 118 in their final year $(46.6 \%)$ of training.

\subsection{Procedure and Measures}

Ethical approval was provided by the School of Psychology Ethics Committee. Once permission from the course directors was given, participants were forwarded an advertisement via email from the researcher inviting them to take part in the study. Informed consent was obtained online from the participants.

Measures included demographics, work characteristics, appraisals, individual differences, coping, childhood experiences, health behaviours and mental health outcomes. Work characteristics, appraisals, coping and mental health outcomes were measured using singleitem questions from the Wellbeing Process Questionnaire (WPQ) [35]. This questionnaire allowed a multi-dimensional approach to be used whilst limiting the associated practical problem of participants filling out lengthy questionnaires. The items in this questionnaire have been shown to correlate with multi-item scales and predict outcomes just as well as these scales [35]. 
Personality was measured using the Big 5 Inventory-10 [36], which measures the big five personality traits in a short-form questionnaire. Perfectionistic personality traits were also measured using the Almost Perfect Scale Revised [37], a questionnaire which includes three variables: standards, order and discrepancy. Core-self evaluations were measured using the Core Self Evaluations Scale (CSES) [38]. The CSES is a 12-item questionnaire that has been developed to operationalise the construct of core selfevaluations, a construct incorporating selfesteem, generalised self-efficacy, locus of control and neuroticism. Imposter feelings (i.e. worries about competency) were also measured using the Imposter Phenomenon scale [39]. The childhood experiences measures included were the Child Abuse and Trauma Scale [40] and the Parentification Inventory [41]. The CATS yields individual scores on three separate subscales: Negative home environment, child physical abuse/punishment and child sexual abuse. The $\mathrm{PI}$ also has three subscales: Parent-focused parentification, sibling-focused parentification and perceived benefits of parentification.

Two additional questions were created; one asked participants whether they themselves had ever suffered from a mental health problem and another asked whether their parents or principal caretaker has ever suffered from a mental health problem. These questions included a list of all psychological disorders outlined in the Diagnostic and Statistical Manual of Mental Health Disorders $5^{\text {th }}$ edition and participants were given a score of one for each experience they selected. Participants were given the opportunity to add extra or non-specified disorders to the list if necessary, or to select "no mental health disorders". Dietary variables included single item questions that asked how often the participants consumed certain products. This included breakfast, fruit and vegetables, biscuits, crisps and chocolate. A single item also measured the amount of exercise participants engaged in on a weekly basis. As alcohol consumption is likely to differ in the amount consumed during weekdays and weekends, this was measured with 4 items. One question asked the participants the number of days they drink alcohol on weekdays (Monday to Thursday) and another asked them the number of days they drink alcohol on the weekends (Friday to Sunday). The other two questions asked how many units of alcohol they normally consume on weekdays and weekends respectively. For the full list of measures see Table 1.

\section{RESULTS}

\subsection{Demographics and Principal Component Analysis}

There were no significant differences for ethnicity. However, there was a significant difference for gender between trainee clinical psychologists and $\mathrm{PhD}$ students $(P<.001)$, with a higher percentage of females in the trainee clinical psychology group. However, this was not the case for the gender distributions between trainee clinical psychologists and psychiatric nursing students or between $\mathrm{PhD}$ students and psychiatric nursing students, with both analyses revealing no significant differences. There was a significant difference for age, with psychiatric nursing students being significantly younger than trainee clinical psychologists $(P<.001)$ and $\mathrm{PhD}$ students $(P=.009)$. However, there were no significant age differences between trainee clinical psychologists and PhD students. First, Principal Components Analyses (PCA) were conducted. Direct oblimin was used as an oblique rotation to extract eigenvalues equalling or exceeding the threshold of 1 . The components are described in Table 2.

To reduce the variables into manageable units and decrease the possibility of chance effects, component scores were created using the Anderson-Rubin method and these scores were used in later analysis. In total, there were 15 components, including three outcomes. Independent variables included job demands, resources, emotion-based coping, seeks social support, negative personality traits, conscientious attitude, relationship focused personality, negative childhood experiences, childhood responsibilities, alcohol consumption, healthy lifestyle and bad diet. Outcomes included perceived stress, job satisfaction and psychological ill health.

\subsection{ANOVA and Post Hocs}

ANOVA analyses were then conducted to reveal any differences between the groups on component scores. The results are presented in Table 3. These analyses revealed that at least one group differed from another on the following components; resources, job demands, perceived stress, emotion-based coping, seeks social 
support, negative personality traits, relationship focused personality, negative childhood experiences, healthy lifestyle and psychological ill health.

Table 1. From left to right: the factors considered in the questionnaire, the individual variables and the description of the measure

\begin{tabular}{|c|c|c|}
\hline Factor & Individual variables & Description of measures \\
\hline Work characteristics & $\begin{array}{l}\text { Demands, control, support, effort, } \\
\text { reward, supervisor relationship. }\end{array}$ & $\begin{array}{l}\text { Single-item measures from the } \\
\text { Wellbeing Process Questionnaire } \\
\text { (WPQ) [35]. }\end{array}$ \\
\hline Appraisals & $\begin{array}{l}\text { Perceived job stress, outside work } \\
\text { stress, hassles, uplifts, job } \\
\text { satisfaction. }\end{array}$ & $\begin{array}{l}\text { Single-item measures of appraisals } \\
\text { from the WPQ. }\end{array}$ \\
\hline Coping & $\begin{array}{l}\text { Problem-focused, seeks social } \\
\text { support, blame-self, wishful } \\
\text { thinking, avoidance. }\end{array}$ & $\begin{array}{l}\text { Single-item measures of coping from } \\
\text { the WPQ. }\end{array}$ \\
\hline Health behaviours & $\begin{array}{l}\text { Alcohol, sleep, exercise, breakfast, } \\
\text { chocolate, crisps, biscuits, fruit \& } \\
\text { vegetables. }\end{array}$ & Single items of health behaviours. \\
\hline Individual differences & $\begin{array}{l}\text { Extraversion, agreeableness, } \\
\text { conscientiousness, neuroticism, } \\
\text { perfectionism variables (standards, } \\
\text { order, discrepancy), imposter } \\
\text { feelings, core self-evaluations. }\end{array}$ & $\begin{array}{l}\text { Big } 5 \text { Inventory-10 [36], Almost- } \\
\text { Perfect Revised Scale [37], Imposter } \\
\text { Phenomenon scale [38], and Core } \\
\text { Self Evaluations Scale [39]. }\end{array}$ \\
\hline $\begin{array}{l}\text { Childhood } \\
\text { experiences }\end{array}$ & $\begin{array}{l}\text { Negative home environment, } \\
\text { sexual abuse, physical abuse, own } \\
\text { mental health disorder, families' } \\
\text { mental health disorder, parent- } \\
\text { focused and sibling-focused } \\
\text { parentification, perceived benefits } \\
\text { of parentification. }\end{array}$ & $\begin{array}{l}\text { Child Abuse and Trauma Scale [40], } \\
\text { Experiences of Mental Health scale, } \\
\text { and Parentification Inventory [41]. }\end{array}$ \\
\hline Outcomes & $\begin{array}{l}\text { Depression, anxiety, burnout, } \\
\text { happiness. }\end{array}$ & $\begin{array}{l}\text { Outcomes were measured using } \\
\text { single-item measures from the WPQ }\end{array}$ \\
\hline Demographics & $\begin{array}{l}\text { Age, gender, ethnicity, year of } \\
\text { training, education level }\end{array}$ & Single item questions \\
\hline
\end{tabular}

Table 2. Results of the principal components analysis

\begin{tabular}{|c|c|c|}
\hline Work characteristics & Factor loading & Cumulative \% variance \\
\hline \multicolumn{3}{|l|}{ Component 1: Resources } \\
\hline Support & 0.836 & $65.4 \%$ \\
\hline Reward & 0.802 & \\
\hline Supervisor relationship & 0.718 & \\
\hline Control & 0.682 & \\
\hline \multicolumn{3}{|c|}{ Component 2: Job demands } \\
\hline Effort & 0.900 & \\
\hline Demands & 0.874 & \\
\hline Appraisals & Factor Loading & Cumulative \% variance \\
\hline \multicolumn{3}{|c|}{ Component 1: Perceived stress } \\
\hline Outside of Work Stress & 0.885 & $63.5 \%$ \\
\hline Job Stress & 0.719 & \\
\hline Hassles & 0.678 & \\
\hline \multicolumn{3}{|c|}{ Component 2: Job satisfaction } \\
\hline Job Satisfaction & 0.857 & \\
\hline Uplifts & 0.746 & \\
\hline
\end{tabular}


Table 2 continued..........

\begin{tabular}{|c|c|c|}
\hline \multirow{2}{*}{\multicolumn{3}{|c|}{$\begin{array}{l}\text { Coping } \\
\text { Component 1: Emotion-based coping }\end{array}$}} \\
\hline & & \\
\hline Avoidance coping & 0.713 & $59.7 \%$ \\
\hline Wishful thinking & 0.699 & \\
\hline Problem-focused coping* & 0.679 & \\
\hline Blame-self coping & 0.677 & \\
\hline \multicolumn{3}{|l|}{ Component 2: Seeks Social Support } \\
\hline Seek social support coping & 0.918 & \\
\hline Individual differences & Factor loading & Cumulative \% variance \\
\hline \multicolumn{3}{|l|}{ Component 1: Negative personality traits } \\
\hline Imposter feelings & 0.918 & $67.8 \%$ \\
\hline Discrepancy (negative perfectionism scale) & 0.899 & \\
\hline Neuroticism & 0.677 & \\
\hline \multicolumn{3}{|l|}{ Component 2: Conscientious attitude } \\
\hline Conscientiousness & 0.819 & \\
\hline Likes high order (perfectionism scale) & 0.768 & \\
\hline Likes high standards (perfectionism scale) & 0.761 & \\
\hline \multicolumn{3}{|l|}{ Component 3: Relationship focused personality } \\
\hline Agreeableness & 0.869 & \\
\hline Extraversion & 0.646 & \\
\hline Childhood experiences & Factor Loading & Cumulative \% variance \\
\hline \multicolumn{3}{|l|}{ Component 1: Negative childhood experiences } \\
\hline Perceived benefits of parentification* & 0.760 & $55.9 \%$ \\
\hline Negative home environment & 0.730 & \\
\hline Own psychiatric history & 0.663 & \\
\hline Sexual abuse & 0.631 & \\
\hline Punishment & 0.603 & \\
\hline Families psychiatric history & 0.442 & \\
\hline \multicolumn{3}{|l|}{ Component 2: Childhood responsibilities } \\
\hline Sibling-focused parentification & 0.882 & \\
\hline Parent-focused parentification & 0.872 & \\
\hline Health Behaviours & Factor Loading & Cumulative \% variance \\
\hline \multicolumn{3}{|l|}{ Component 1: Alcohol consumption } \\
\hline Units of alcohol consumed (weekdays) & 0.833 & 51.184 \\
\hline Number of days alcohol is consumed (weekdays) & 0.809 & \\
\hline Units of alcohol consumed (weekends) & 0.787 & \\
\hline Number of days alcohol is consumed (weekends) & 0.767 & \\
\hline \multicolumn{3}{|l|}{ Component 2: Healthy lifestyle } \\
\hline Fruit and vegetables consumption & 0.714 & \\
\hline Breakfast consumption & 0.713 & \\
\hline Amount of exercise (weekly) & 0.642 & \\
\hline \multicolumn{3}{|l|}{ Component 3: Bad diet } \\
\hline Biscuits consumption & 0.764 & \\
\hline Chocolate consumption & 0.749 & \\
\hline Crisps consumption & 0.608 & \\
\hline \multicolumn{3}{|l|}{ Health outcomes } \\
\hline \multicolumn{3}{|l|}{ Component 1: Psychological ill health } \\
\hline Depression & 0.877 & $62.117 \%$ \\
\hline Happiness* & 0.822 & \\
\hline Anxiety & 0.775 & \\
\hline Burnout & 0.663 & \\
\hline
\end{tabular}

Bonferonni post hoc comparison tests were then conducted. Trainee clinical psychologists reported significantly more resources than psychiatric nursing students $(P=.05)$ and $\mathrm{PhD}$ students $(P=.002)$. They also reported more job demands than the other groups $(P<.001)$ and 
engaging in more seeking social support coping than PhD students $(P=.05)$. Trainee clinical psychologists reported higher perceived stress than psychiatric nursing students $(P=.042)$ and PhD students $(P<.001)$ and more negative childhood experiences than PhD students $(P=$ .015). Furthermore, trainee clinical psychologists reported significantly more psychological ill health than PhD students $(P=.024)$. Psychiatric nursing students reported more emotion-based coping than both of the other groups $(P<.001)$ and engaged in a less healthy lifestyle than both the other groups $(P<.001)$. Psychiatric nursing students reported significantly higher on both the negative personality traits $(P=.015)$ and the relationship focused personality traits components $(P=.049)$ than $\mathrm{PhD}$ students.

\subsection{Regressions}

A series of regression analyses were then carried out to investigate the associations of the multiple independent variables to psychological ill health, perceived stress and job satisfaction. The independent variables were selected on the basis of manual backwards selection, taking into account significance level and standardised beta weights. In all regressions and before backwards selection, participants' age, gender, year of training and ethnicity were included as independent variables. However, they did not emerge as significant predictors in many of the tests and those that did were included in the analyses. Therefore, these variables have not confounded any of the significant relationships presented here. Intercorrelations of the independent variables showed no relationships over .8, therefore suggesting no issues with multicollinearity. A series of analyses including interaction terms were also conducted, but no significant interaction effects were found. All regressions were significant at $P<.001$.

The regressions presented in Table 4 shows the overarching structure of the variables by taking into account all participants. Demands and core self-evaluations were the most important predictors of psychological ill health by beta weight. For perceived stress, job demands and negative childhood experiences were the most important predictors and for job satisfaction the most important were resources and core selfevaluations. The variables presented in the table account for $59.5 \%$ of the variance in psychological ill health, $38.5 \%$ of the variance in perceived stress and $44.3 \%$ of the variance in job satisfaction.

The regressions presented in Table 5 include the trainee clinical psychologist group only. Job demands and core self-evaluations were the most important predictors for both psychological ill health and perceived stress by beta weight. For job satisfaction, the most important predictors were resources and relationship focused personality. The regressions account for $55.3 \%$ of the variance in psychological ill health, $35.8 \%$ of the variance in perceived stress and $39.2 \%$ of the variance in job satisfaction.

The regressions presented in Table 6 include psychiatric nursing students only. Job demands and core self-evaluations were the most important predictors for psychological ill health by beta weight. For perceived stress, the most important predictors were job demands and

\section{Table 3. ANOVA table displaying differences between groups}

\begin{tabular}{lllll}
\hline Factor & $\boldsymbol{d f}$ & $\boldsymbol{F}$ & $\boldsymbol{P}$ & $\boldsymbol{p a r t i a l}^{\boldsymbol{\eta}^{2}}$ \\
\hline Resources & 2,507 & 6.223 & .002 & .024 \\
Job demands & 2,507 & 11.934 & $<.001$ & .045 \\
Perceived stress & 2,509 & 11.553 & $<.001$ & .043 \\
Job satisfaction & 2,509 & 2.068 & .127 & - \\
Emotion-based coping & 2,511 & 12.929 & $<.001$ & .048 \\
Seeks social support & 2,511 & 3.090 & .046 & .012 \\
Negative personality traits & 2.511 & 3.956 & .020 & .015 \\
Conscientious attitude & 2,511 & 2.677 & .070 & - \\
Relationship focused personality & 2,511 & 3.433 & .033 & .013 \\
Negative childhood experiences & 2,512 & 4.549 & .011 & .017 \\
Childhood responsibilities & 2,512 & 1.615 & .200 & - \\
Alcohol consumption & 2,505 & 1.304 & .272 & - \\
Healthy lifestyle & 2,505 & 9.906 & $<.001$ & .038 \\
Bad diet & 2,505 & .917 & .400 & - \\
Psychological ill health & 2,509 & 3.734 & .025 & .014 \\
\hline
\end{tabular}


Table 4. Regressions for the whole sample

\begin{tabular}{llllll}
\hline Psychological ill health & $\mathbf{B}$ & $\mathbf{S E ~ B}$ & $\boldsymbol{\beta}$ & $\mathbf{t}$ & $\mathbf{P}$ \\
\hline Resources & -.059 & .033 & -.061 & -1.822 & .069 \\
Job demands & .267 & .030 & .270 & 8.816 & .000 \\
Emotion-based coping & .101 & .039 & .102 & 2.587 & .010 \\
Alcohol consumption & .099 & .029 & .100 & 3.360 & .001 \\
Healthy lifestyle & -.082 & .029 & -.083 & -2.793 & .005 \\
Negative personality traits & .120 & .047 & .121 & 2.550 & .011 \\
Conscientious attitude & .060 & .032 & .060 & 1.866 & .063 \\
Relationship focused personality & -.098 & .031 & -.099 & -3.197 & .001 \\
Negative childhood experiences & .121 & .029 & .129 & 4.093 & .000 \\
Core self-evaluations & -.560 & .084 & -.338 & -6.685 & .000 \\
Model: $\mathrm{R}=.771, \mathrm{R}^{2}=.595$ & & & & $\mathrm{~F}: 72.174$ & .000 \\
\hline Perceived stress & $\mathbf{B}$ & $\mathbf{S E ~ B}$ & $\boldsymbol{\beta}$ & $\mathbf{t}$ & $\mathbf{P}$ \\
\hline Resources & -.072 & .040 & -.073 & -1.792 & .074 \\
Job demands & .396 & .037 & .398 & 10.663 & .000 \\
Healthy lifestyle & -.065 & .035 & -.065 & -1.828 & .068 \\
Negative personality traits & .116 & .053 & .116 & 2.172 & .030 \\
Negative childhood experiences & .123 & .037 & .131 & 3.342 & .001 \\
Childhood responsibilities & -.070 & .037 & -.070 & -1.911 & .057 \\
Core self-evaluations & -.232 & .096 & -.128 & -2.401 & 017 \\
Model: $\mathrm{R}=.620, \mathrm{R}^{2}=.385$ & & & & $\mathrm{~F}: 44.100$ & .000 \\
\hline Job satisfaction & $\mathbf{B}$ & $\mathbf{S E} \mathbf{B}$ & $\boldsymbol{\beta}$ & $\mathbf{t}$ & $\mathbf{P}$ \\
\hline Resources & .431 & .038 & .442 & 11.460 & .000 \\
Job demands & -.136 & .034 & -.138 & -3.962 & .000 \\
Alcohol consumption & -.082 & .033 & -.083 & -2.460 & .014 \\
Relationship focused personality & .132 & .035 & .133 & 3.760 & .000 \\
Childhood responsibilities & -.092 & .034 & -.093 & -2.707 & .007 \\
Core self-evaluations & .331 & .065 & .200 & 5.104 & .000 \\
Model: $\mathrm{R}=.666, \mathrm{R}^{2}=.443$ & & & & $\mathrm{~F}: 65.704$ & .000 \\
\hline & & & & & \\
\hline
\end{tabular}

Table 5. Regressions for the trainee clinical psychologist group

\begin{tabular}{llllll}
\hline Psychological ill health & $\mathbf{B}$ & $\mathbf{S E ~ B}$ & $\boldsymbol{\beta}$ & $\mathbf{t}$ & $\mathbf{P}$ \\
\hline Job demands & .182 & .046 & .215 & 3.921 & .000 \\
Healthy lifestyle & -.087 & .047 & -.101 & 1.849 & .066 \\
Negative personality traits & .180 & .063 & .221 & 2.878 & .005 \\
Relationship focused personality & -.132 & .050 & -.156 & -2.623 & .010 \\
Negative childhood experiences & .097 & .051 & .115 & 1.994 & .049 \\
Core self-evaluations & -.503 & .125 & -.323 & -4.014 & .000 \\
Model: $\mathrm{R}=.744, \mathrm{R}^{2}=.553$ & & & & $\mathrm{~F}: 32.590$ & .000 \\
\hline Perceived stress & $\mathbf{B}$ & $\mathbf{S E ~ B}$ & $\boldsymbol{\beta}$ & $\mathbf{t}$ & $\mathbf{P}$ \\
\hline Job demands & .316 & .058 & .345 & 5.427 & .000 \\
Core self-evaluations & -.724 & .106 & -.434 & -6.816 & .000 \\
Model: $\mathrm{R}=.598, \mathrm{R}^{2}=.358$ & & & & $\mathrm{~F}: 45.478$ & .000 \\
\hline Job satisfaction & $\mathbf{B}$ & $\mathbf{S E ~ B}$ & $\boldsymbol{\beta}$ & $\mathbf{t}$ & $\mathbf{P}$ \\
\hline Resources & .441 & .078 & .396 & 5.633 & .000 \\
Job demands & -.145 & .061 & -.156 & -2.401 & .017 \\
Relationship focused personality & .178 & .062 & .193 & 2.862 & .005 \\
Core self-evaluations & .240 & .122 & .141 & 1.970 & .051 \\
Model: $\mathrm{R}=.626, \mathrm{R}^{2}=.392$ & & & & $\mathrm{~F}: 65.704$ & .000 \\
\hline
\end{tabular}

negative childhood experiences and for job satisfaction, the most important predictors were resources and negative childhood experiences. The regressions account for $70.6 \%$ of the variance in psychological ill health, $49.1 \%$ of the variance in perceived stress and $41.9 \%$ of the variance in job satisfaction. 
Table 7 presents the regressions including $\mathrm{PhD}$ students only. Core self-evaluations and emotion-based coping were the most important predictors for psychological ill health. Job demands and core self-evaluations were the most important predictors for perceived stress, and for job satisfaction the most important predictors were resources and core selfevaluations. The variables presented in the table below account for $62.9 \%$ of the variance in psychological ill health, $37.6 \%$ of the variance in perceived stress and $49.1 \%$ of the variance in job satisfaction.

Table 6. Regressions for the psychiatric nursing student group

\begin{tabular}{llllll}
\hline Psychological ill health & $\mathbf{B}$ & SE B & $\boldsymbol{\beta}$ & $\mathbf{t}$ & $\mathbf{P}$ \\
\hline Job demands & .405 & .072 & .349 & 5.599 & .000 \\
Resources & -.190 & .078 & -.164 & -2.423 & .018 \\
Emotion-based coping & .247 & .095 & .199 & 2.600 & .011 \\
Alcohol consumption & .159 & .072 & .132 & 2.202 & .030 \\
Negative childhood experiences & .134 & .051 & .173 & 2.609 & .011 \\
Core self-evaluations & -.613 & .173 & -.318 & -3.538 & .001 \\
Model: $\mathrm{R}=.840, \mathrm{R}^{2}=.706$ & & & & $\mathrm{~F}: 33.156$ & .000 \\
\hline Perceived stress & $\mathbf{B}$ & $\mathbf{S E ~ B}$ & $\boldsymbol{\beta}$ & $\mathbf{t}$ & $\mathbf{P}$ \\
\hline Job demands & .510 & .085 & .477 & 6.032 & .000 \\
Resources & -.198 & .086 & -.186 & -2.313 & .023 \\
Alcohol consumption & .215 & .086 & .194 & 2.499 & .014 \\
Negative childhood experiences & .211 & .057 & 2.96 & 3.712 & .000 \\
Model: $\mathrm{R}=.700, \mathrm{R}^{2}=.491$ & & & & $\mathrm{~F}: 20.458$ & .000 \\
\hline Job satisfaction & $\mathbf{B}$ & $\mathbf{S E ~ B}$ & $\boldsymbol{\beta}$ & $\mathbf{t}$ & $\mathbf{P}$ \\
\hline Resources & .409 & .084 & .419 & 4.822 & .000 \\
Job demands & -.198 & .083 & -.202 & -2.393 & .019 \\
Alcohol consumption & -.162 & .084 & -.160 & -1.929 & .057 \\
Negative childhood experiences & -.175 & .056 & -.269 & -3.152 & .002 \\
Model: $\mathrm{R}=.647, \mathrm{R}^{2}=.419$ & & & & $\mathrm{~F}: 15.322$ & .000 \\
\hline
\end{tabular}

Table 7. Regressions for the PhD student group

\begin{tabular}{llllll}
\hline Psychological ill health & $\mathbf{B}$ & $\mathbf{S E ~ B}$ & $\boldsymbol{\beta}$ & $\mathbf{t}$ & $\mathbf{P}$ \\
\hline Job demands & .182 & .045 & .177 & 4.033 & .000 \\
Resources & -.086 & .042 & -.096 & -2.075 & .039 \\
Emotion-based coping & .207 & .051 & .204 & 4.089 & .000 \\
Healthy lifestyle & -.163 & .042 & -.158 & -3.868 & .000 \\
Bad diet & -.080 & .042 & -.077 & -1.880 & .061 \\
Conscientious attitude & .095 & .040 & .103 & 2.387 & .018 \\
Relationship focused personality & -.078 & .040 & -.081 & -1.924 & .056 \\
Core self-evaluations & -.822 & .086 & -.506 & -9.571 & .000 \\
Model: $\mathrm{R}=.793, \mathrm{R}^{2}=.629$ & & & & $\mathrm{~F}: 50.400$ & .000 \\
\hline Perceived stress & $\mathbf{B}$ & $\mathbf{S E ~ B}$ & $\boldsymbol{\beta}$ & $\mathbf{t}$ & $\mathbf{P}$ \\
\hline Job demands & .354 & .055 & .345 & 6.392 & .000 \\
Healthy lifestyle & -.140 & .053 & -.136 & -2.625 & .009 \\
Conscientious attitude & .124 & .050 & .134 & 2.487 & .014 \\
Childhood responsibilities & -.144 & .056 & -.134 & -2.585 & .010 \\
Core self-evaluations & -.562 & .091 & -.344 & -6.205 & .000 \\
Model: $\mathrm{R}=.613, \mathrm{R}^{2}=.376$ & & & & $\mathrm{~F}: 28.988$ & .000 \\
\hline Job satisfaction & $\mathbf{B}$ & $\mathbf{S E ~ B}$ & $\boldsymbol{\beta}$ & $\mathbf{t}$ & $\mathbf{P}$ \\
\hline Resources & .482 & .049 & .501 & 9.904 & .000 \\
Childhood responsibilities & -.144 & .052 & -.126 & -2.746 & .006 \\
Core self-evaluations & .546 & .088 & .318 & 6.202 & .000 \\
Model: $\mathrm{R}=.701, \mathrm{R}^{2}=.491$ & & & & $\mathrm{~F}: 79.369$ & .000 \\
\hline
\end{tabular}




\subsection{Mediation Analysis}

The Z Sobel test, using Hayes' [42] process tool for SPSS was used to investigate whether perceived stress mediates the relationship between demands and outcomes. With the outcome as psychological ill health, the total effect of $X$ on $Y$ was $.4320(\mathrm{Cl}$ : .3539-.5102, $\mathrm{P}<.001)$ with a direct effect of $X$ on $Y$ of .1408 (Cl: .0673-.2142, $P<.001)$. The indirect effect was .2913 and the confidence interval was .2352 to .3506. As this confidence interval does not contain zero, the indirect effect can be considered significant [42]. With the outcome as job satisfaction, the total effect of $X$ on $Y$ was .2912 (Cl: $-.3748,-.2077, P<.001)$ with a direct effect of $\mathrm{X}$ on $\mathrm{Y}$ of $.1400(\mathrm{Cl}:-.2323,-.0478$, $\mathrm{P}=.003)$. The indirect effect was -.1512 and with a confidence interval of -.2060 to -.1012 . As this confidence interval does not contain zero, this effect is also considered significant.

We also tested whether perceived stress mediates the relationship between resources and outcomes. Using the same procedure and with the outcome psychological ill health, the analysis revealed a total effect of $\mathrm{X}$ on $\mathrm{Y}$ at $-.3860(\mathrm{Cl}$ : $.4652,-.3068, p<.001)$ with a direct effect of $X$ on $\mathrm{Y}$ at -.2081 ( $\mathrm{Cl}:-.2730,-.1433, \mathrm{P}<.001)$. The indirect effect was -.1779 and as the confidence interval $(-.2328,-.1270)$ does not contain zero, this can be considered significant [42]. For the outcome as job satisfaction, the analysis revealed a total effect of $X$ on $Y .5873$ (.5176$.6570, p<.001)$ and a direct effect of $X$ on $Y$ .5225 (.4519-.5932, $p<.001)$. The indirect effect of $X$ on $Y$ was .0648 (Cl: .0375-.0980) and as the confidence interval does not contain zero, this effect is considered significant.

Taken together, these findings demonstrate that perceived stress partially mediates the relationship between demands/resources and outcomes. Fig. 1 summarises the overall structure of the analysis.

\section{DISCUSSION}

This study adopted a multi-dimensional framework to investigate stress in two groups of mental health students. The partially mediating role of perceived stress supports other research using this approach [34] and demonstrates that the appraisal of stress is an important outcome in itself when considering well-being policy. In addition to providing information on associated factors, the analysis revealed a number of interesting differences between the groups.

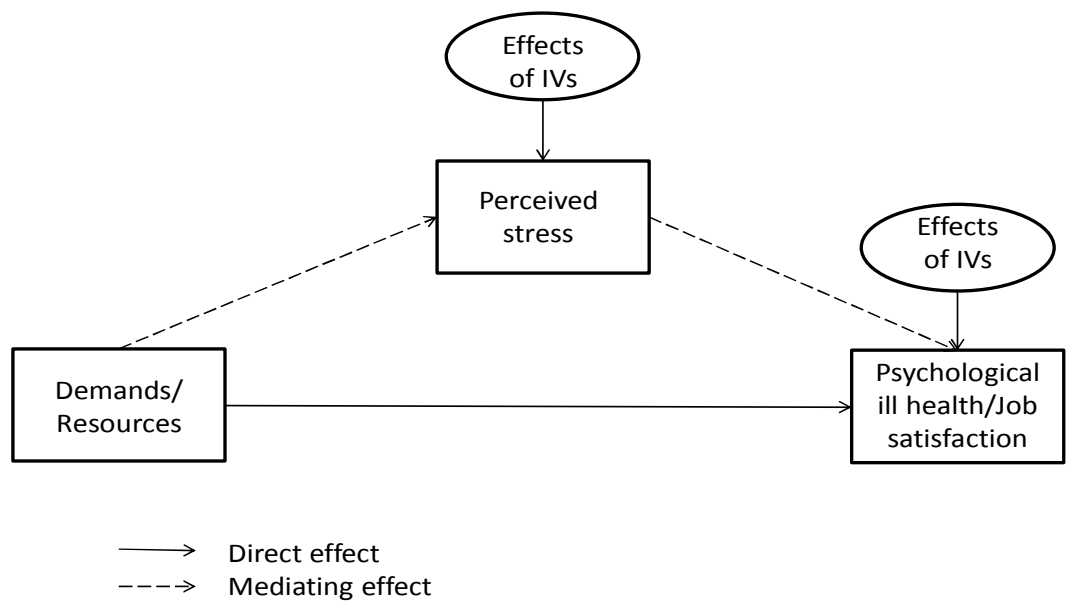

Fig. 1. Model shows the direct effects of independent variables (IVs) on perceived stress, psychological ill health and job satisfaction as well as the interactive effect of perceived stress on demands and resources 
Trainee clinical psychologists reported higher demands and higher perceived stress than psychiatric nursing students and PhD students. They also reported higher levels of psychological ill health than $\mathrm{PhD}$ students. However, trainee clinical psychologists reported having more protective factors such as resources and seeking social support at their disposal than other groups. Despite this, high resources and seeking social support were not associated with perceived stress or psychological ill health in any of the trainee regressions. This suggests that other factors, such as individual differences variables, could be more important. Indeed, individual differences such as personality were the factors most strongly associated with outcomes for this group.

The finding that psychiatric nursing students reported significantly less resources than trainee clinical psychologists will not be surprising to many readers. A report by the Royal College of Nursing [43] reiterated their repeatedly raised concerns that government cuts to mental health services, as well as cuts to the nursing workforce and a failure to plan for the future has left the NHS understaffed and patient care compromised. They pointed towards the 3,300 psychiatric nursing posts across the UK that have been cut in the last four years and how the most experienced nurses have been disproportionately lost in these cuts, resulting in a loss of these skills and experience in the profession. Within this context, it is not surprising that psychiatric nursing students feel under resourced compared to trainee clinical psychologists, who are engaged in a training programme which, in comparison, tends to be well resourced and well protected in the U.K. It is therefore important that psychiatric nursing students do not only receive their training in environments that have safe staffing numbers, but also that the staff in these environments have the appropriate experience and skills to provide the necessary support and supervision. It is too often the case that nursing students can be used as an extra pair of hands on the ward, rather than being given the appropriate learning environment they need.

It is essential for nurse educators to discover the coping strategies employed by psychiatric nursing students so that they can be helped to cope effectively during their training. In this study, alcohol consumption was associated with all three outcomes for psychiatric nursing students, but not in any of the regressions for the other groups, suggesting this could be a particularly important coping strategy employed by them. Psychiatric nursing students also reported the highest levels of emotion-based coping strategies and this factor was associated with higher psychological ill health. The potential greater use of academic and theoretical models in the training of postgraduate students could be relevant to this finding. For example, in a systematic review of stress and coping in nursing students, Galbaith and Brown [44] concluded that training programmes should only incorporate stress interventions that take into consideration current theories of stress.

Trainee clinical psychologists reported a higher incidence of negative childhood experiences than $\mathrm{PhD}$ students and this was found to be associated with poorer psychological ill health for this group. Furthermore, negative childhood experiences were associated with all three outcomes for the psychiatric nursing students but not in any of the PhD student regressions. This updated information is in line with previous research conducted looking at childhood experiences in mental health professionals and provides additional support for the idea that mental health professionals are likely to themselves be "wounded" [24-27]. It is therefore important that multi-factor research looking into stress in mental health professionals accounts for such experiences.

There are limitations to the present study that should be acknowledged. The study allowed the examination of associations, but it cannot determine the direction of the effects. Therefore, causality cannot be inferred. However, we hope to address this in future work by focusing on the impact of multiple factors on stress outcomes longitudinally for these groups. Furthermore, our study may have suffered from other common limitations found in questionnaire data, such as response bias. For example, as this study used convenience sampling, those participants who responded to the questionnaire could be individuals more likely to respond at the extremes of the scales. We can also not be completely sure that trainee clinical psychologists, psychiatric nursing students and $\mathrm{PhD}$ students respond to questionnaires in the same way, as characteristics of the groups could have an impact on responses. For example, the reflective practice encouraged in the mental health professions could influence responses. 


\section{CONCLUSION}

Mental health students in the U.K. are exposed to many stressors during training, but very few researchers have considered the effects of multiple factors on outcomes. In this study, we focused on both the personal and professional lives of trainee clinical psychologists and psychiatric nursing students, two groups that represent the future of the mental health workforce in the U.K. Investigating stress in mental health students is important, particularly during a time of increased pressure on $\mathrm{NHS}$ mental health services. The data presented here can feed into the effective management of U.K. mental health training.

\section{ETHICAL APPROVAL}

Ethical approval was provided by Cardiff University School of Psychology.

\section{COMPETING INTERESTS}

Authors have declared that no competing interests exist.

\section{REFERENCES}

1. Dickinson T, Wright KM. Stress and burnout in forensic mental health nursing: A literature review. Br. J. Nurs. 2008;17(2): 81-87.

DOI:10.12968/bjon.2008.17.2.28133.

2. Edwards D, Burnard P, Coyle D, Fothergill A, Hannigan B. Stress and burnout in community mental health nursing: A review of the literature. J. Psychiatr Ment Health Nurs. 2000;7(1):7-14.

DOI: 10.1046/j.1365-2850.2000.00258.x.

3. Hannigan B, Edwards D, Burnard P. Stress and stress management in clinical psychology: Findings from a systematic review. J. Ment Health. 2004;13(3):235-45. DOI: $10.1080 / 09638230410001700871$.

4. Nolan G, Ryan D. Experience of stress in psychiatric nursing students in Ireland. Nurs Stand. 2008;22(43):35-43.

DOI: 10.7748/ns2008.07.22.43.35.c6583.

5. Pakenham KI, Stafford-Brown J. Stress in clinical psychology trainees: Current research status and future directions. Aust Psychol. 2012;47(3):147-55.

DOI: $10.1111 / \mathrm{j} .1742-9544.2012 .00070$.

6. Tully A. Stress, sources of stress and ways of coping among psychiatric nursing students. J. Psychiatr Ment Health Nurs. 2004;11(1):43-47.

DOI: 10.1111/j.1365-2850.2004.00682.x.

7. Priest $H$, Roberts $P$, Dent $H$, Hunt $T$, Weston D, Chell A, Blincoe CA. Preparing for collaborative working in mental health: An interprofessional education project with clinical psychology trainees and nursing students. J. Ment Health Train, Educ Pract. 2011;6(1):47-57.

DOI: $10.1108 / 17556221111136161$.

8. Shete AN, Garkal KD. A study of stress, anxiety and depression among postgraduate medical students. J. Health Res. 2015;2(2):119-23.

DOI: $10.4103 / 2348-334.153255$.

9. NHS Staff Survey; 2013. Available:http://www.nhsstaffsurveys.com/P age/1006/Latest-Results/2013-Results/ (Accessed 01 February 2015).

10. Cushway D, Tyler PA. Stress and coping in clinical psychologists. Stress Med. 1994; 10(1):35-42.

DOI: $10.1002 /$ smi.2460100107.

11. Goldberg L. Manual of the general health questionnaire. Windsor: Nelson; 1978.

12. Mark G, Smith AP. Occupational stress, job characteristics, coping and the mental health of nurses. Br. J. Health Psychol. 2012;17(3):505-21.

DOI: 10.1111/j.2044-8287.2011.02051.

13. Watson R, Calman L, Norman I, Redfern S, Murrells T. Assessing clinical competence in student nurses. J. Clin Nurs. 2002;11(4): 554-55.

DOI: 10.1046/j.1365-2702.2002.00590.x.

14. Watson R, Dreary I, Thompson D, Li G. A study of stress and burnout in nursing students in Hong Kong: A questionnaire survey. Int. J. Nurs Stud. 2008;45(10): 1534-1542.

DOI: 10.1016/j.ijnurstu.2007.11.003.

15. Deary IJ, Watson R, Hogston R. A longitudinal cohort study of burnout and attrition in nursing students. J. Adv. Nurs. 2003;43(1):71-81.

DOI: 10.1046/j.1365-2648.2003.02674.x.

16. Buchan J, Seccombe I. More nurses, working differently? A review of the U.K. nursing labour market 2002 to 2003, London: Royal College of Nursing; 2003.

17. Hung BJ, Huang $X Y$, Lin MJ. The first experiences of clinical practice of psychiatric nursing students in Taiwan: A phenomenological study. J. Clin Nurs. 2009;18(22):3126-35.

DOI: 10.1111/j.1365-2702.2008.02610.x. 
18. Jones MC, Johnston DW. Distress, stress and coping in first-year student nurses. J. Adv. Nurs. 1997;26(3):475-82.

DOI:10.1046/j.1365-2648.1997.t01-500999.x

19. Buchanan D, Huczynski A. Organizational Behaviour. $5^{\text {th }}$ ed. London: Prentice Hall; 2004.

20. McGowan B. Self-reported stress and its effects on nurses. Nurs Stand. 2001; 15(42):33-38.

DOI: $10.7748 / n s 2001.07 .15 .42 .33 . c 3050$.

21. Le Blanc $P$, de Jonge J, Schaufeli WB. Job stress and health. In: Chmiel $\mathrm{N}$, editor. Introduction to work and organizational psychology: A European perspective. Malden: Blackwell Publishing; 2000.

22. Kipping CJ. Stress in mental health nursing. Int. J. Nurs Stud. 2000;37(3):207-18.

DOI: 10.1016/S0020-7489(00)00006-7.

23. Jung $\mathrm{C}$. The wounded healer. American Psychiatric Association; 1963.

24. Elliott DM, Guy JD. Mental health professionals versus non-mental health professionals: Childhood trauma and adult functioning. Prof. Psychol Res Pract. 1993; 24(1):83-90.

DOI: $10.1037 / / 0735-7028.24 .1 .83$

25. Frank $\mathrm{H}$, Paris J. Psychological factors in the choice of psychiatry as a career. Can J. Psychiatr. 1987;32:118-22.

26. Rajagopal S, Rehill KS, Godfrey E. Psychiatry as a career choice compared with other specialities: A survey of medical students. Psychiatr Bull. 2004;28(12):44446. DOI: 10.1192/pb.28.12.444.

27. Pope KS, Feldman-Summers S. National survey of psychologists' sexual and physical abuse history and their evaluation of training and competence in these areas. Prof Psychol Res Pract. 1992;23:353-61. DOI: 10.1037//0735-7028.23.5.353.

28. Wicki M, Kuntsche E, Gmel G. Drinking at European universities? A review of students' alcohol use. Addict Behav. 2010; 35(11):913-24.

DOI: 10.1016/j.addbeh.2010.06.015.

29. Pickard M, Bates L, Dorian M, Greig H, Saint D. Alcohol and drug use in secondyear medical students at the University of Leeds. Med Educ. 2000;34(2):148-50. DOI: 10.1046/j.1365-2923.2000.00491.x.

30. TyssenR, Vaglum $\mathrm{P}$, Aasland OG, Gronvold NT, Ekeberg O. Use of alcohol to cope with tension and its relation to gender, years in medical school and hazardous drinking: A study of two nationwide norwegian samples of medical students.

Addict. 1998;93(9):1341-49.

DOI:10.1046/j.1360-

0443.1998.93913415.x

31. Oliver G, Wardle J. Perceived effects of stress on food choice. Physiol Behav. 1999;66(3):511-15.

DOI: 10.1016/S0031-9384(98)00322-9.

32. Lee RLT, Loke AJTY. Health promoting behaviours and psychosocial well-being of university students in Hong Kong. Pub Health Nurs. 2005;22(3):209-20.

DOI: 10.1111/j.0737-1209.2005.220304.x.

33. Smith AP, McNamara R, Wellens $B$. Combined effects of occupational health hazards. Norwich: HSE Books; 2004.

34. Mark GM, Smith AP. Stress models: A review and suggested new direction. In: Houdmont J, Leka S, editors. Occupational Health Psychology: European Perspectives on Research, Education and Practice. (111-44). Nottingham: Nottingham University Press. 2008;3.

35. Williams G. Developing short, practical measures of well-being. In: Anderson M, editor. Contemporary Ergonomics and Human Factors. London: Taylor \& Francis; 2012.

36. Rammstedt B, John OP. Measuring personality in one minute or less: A 10-item short version of the Big Five Inventory in English and German. J. Res Pers. 2007; 41(1):203-12.

DOI: 10.1016/j.jrp.2006.02.001.

37. Slaney RB, Rice KG, Mobley M, Trippi J, Ashby JS. The revised almost perfect scale. Meas Eval Couns Dev. 2001;34(3):130-45.

38. Clance PR. The Imposter Phenomenon: When success makes you feel like a fake. Bantam Books; 1985.

39. Judge TA, Erez A, Bono JE, Thoresen CJ. The core self-evaluations scale: Development of a measure. Pers Psychol. 2003;56(2):303-31. DOI: 10.1111/j.1744-6570.2003.tb00152.x.

40. Sanders B, Becker-Lausen E. The measurement of psychological maltreatment: Early data on the child abuse and trauma scale. Child Abuse Negl. 1995;19(3):315-23.

DOI: 10.1016/S0145-2134(94)00131-6.

41. Hooper LM, Doehler K, Wallace SA, Hannah NJ. The parentification inventory: Development, validation and crossvalidation. Am J. Fam Ther. 2011;39(3): 226-41.

DOI: 10.1080/01926187.2010.531652. 
42. Hayes AF. Introduction to mediation, moderation and conditional process analysis: A regression-based approach. New York: Guildford Press; 2013.

43. Royal College of Nursing. Turning back the clock? RCN report on mental health services in the U.K; 2014.

Available:http://www.rcn.org.uk/data/assets /pdf file/0004/600628/004772.pdf

(Accessed 01 Feb 2015)

44. Galbraith ND, Brown KE. Assessing intervention effectiveness for reducing stress in student nurses: Quantitative systematic review. J. Adv Nurs. 2011; 67(4):709-21.

DOI:10.1111/j.1365-2648.2010.05549.x.

(c) 2015 Galvin and Smith; This is an Open Access article distributed under the terms of the Creative Commons Attribution License (http://creativecommons.org/licenses/by/4.0), which permits unrestricted use, distribution and reproduction in any medium, provided the original work is properly cited.

Peer-review history:

The peer review history for this paper can be accessed here: http://www.sciencedomain.org/review-history.php?iid=1174\&id=21\&aid=9470 